\title{
Cholecystectomy Concomitant with Laparoscopic Gastric Bypass: A Trend Analysis of the Nationwide Inpatient Sample from 2001 to 2008
}

\author{
Mathias Worni • Ulrich Guller • Anand Shah • \\ Mihir Gandhi • Jatin Shah • Dimple Rajgor • \\ Ricardo Pietrobon • Danny O. Jacobs • Truls Østbye
}

Published online: 20 December 2011

(C) Springer Science+Business Media, LLC 2011

\begin{abstract}
Background Gallstone formation is common in obese patients, particularly during rapid weight loss. Whether a concomitant cholecystectomy should be performed during
\end{abstract}

This work has been presented in part at the Annual Congress of the Swiss Society for Surgery (Geneva, Switzerland, May 2011).

M. Worni $(\triangle) \cdot$ A. Shah $\cdot$ M. Gandhi $\cdot$ J. Shah $\cdot$ D. Rajgor $\cdot$

R. Pietrobon

Research on Research Group, Department of Surgery,

Duke University Medical Center,

DUMC 3094,

Durham, NC 27710, USA

e-mail: mathias.worni@duke.edu

M. Worni $\cdot$ U. Guller

Department of Visceral Surgery and Medicine, University of Bern,

Bern, Switzerland

D. O. Jacobs

Department of Surgery, Duke University Medical Center,

Durham, NC, USA

M. Gandhi

Singapore Clinical Research Institute,

Singapore, Singapore

M. Gandhi · T. Østbye

Duke-NUS Graduate Medical School,

Singapore, Singapore

T. Østbye

Department of Community and Family Medicine,

Duke University Medical Center,

Durham, NC, USA

U. Guller

Oncology and Hematology,

Cantonal Hospital St. Gallen,

St. Gallen, Switzerland laparoscopic gastric bypass surgery is still contentious. We aimed to analyze trends in concomitant cholecystectomy and laparoscopic gastric bypass surgery (2001-2008), to identify factors associated with concomitant cholecystectomy, and to compare short-term outcomes after laparoscopic gastric bypass with and without concomitant cholecystectomy.

Methods We used data from adults undergoing laparoscopic gastric bypass for obesity from the Nationwide Inpatient Sample. The Cochran-Armitage trend test was used to assess changes over time. Unadjusted and risk-adjusted generalized linear models were performed to assess predictors of concomitant cholecystectomy and to assess postoperative short-term outcomes.

Results A total of 70,287 patients were included: mean age was 43.1 years and $81.6 \%$ were female. Concomitant cholecystectomy was performed in $6,402(9.1 \%)$ patients. The proportion of patients undergoing concomitant cholecystectomy decreased significantly from $26.3 \%$ in 2001 to $3.7 \%$ in 2008 ( $p$ for trend $<0.001$ ). Patients who underwent concomitant cholecystectomy had higher rates of mortality (unadjusted odds ratios [OR], 2.16; $p=0.012$ ), overall postoperative complications (risk-adjusted OR, 1.59; $p=$ 0.001 ), and reinterventions (risk-adjusted OR, 3.83; $p<$ 0.001 ), less frequent routine discharge (risk-adjusted OR, $0.70 ; p=0.05$ ), and longer adjusted hospital stay (median difference, 0.4 days; $p<0.001$ ).

Conclusions Concomitant cholecystectomy and laparoscopic gastric bypass surgery have decreased significantly over the last decade. Given the higher rates of postoperative complications, reinterventions, mortality, as well as longer hospital stay, concomitant cholecystectomy should only be considered in patients with symptomatic gallbladder disease.

Keywords Bariatric surgery - Laparoscopic gastric bypass . Cholecystectomy · Gallstones · Adverse outcomes 


\section{Introduction}

Obesity has reached epidemic proportions in the USA and, with the prevalence of obesity of approximately $34 \%$ [1], bariatric surgery is performed more frequently than ever before [2, 3]. Weight loss surgery is a fast and mostly permanent way to lose weight for those with severe obesity $[4,5]$. Bariatric surgery not only decreases morbidity and mortality in obese patients $[4,6]$, but also has been estimated to reduce health care costs up to $45 \%$ by 5 years postoperatively $[6,7]$. However, the formation of gallstones in these patients remains a subject of concern $[8,9]$. Despite the benefits of bariatric surgery, obesity and rapid weight loss increase the risk of gallstone formation [8-10] with a 1 -year cumulative incidence after bariatric surgery ranging from $30 \%$ to $53 \%$ [11, 12]. Although routine prophylactic cholecystectomy [13-15] can be performed to remove gallstones or to prevent gallstone formation, several alternative approaches have been suggested regarding the management of the gallbladder during bariatric surgery. These include cholecystectomy only after preoperatively detected gallbladder pathology by ultrasound $[16,17]$, cholecystectomy after intraoperative verification of gallstones with ultrasound [11, 18], routine administration of ursodeoxycholic acid to all patients to prevent gallstone formation [11, 19, 20], and no treatment for asymptomatic patients before or after surgery $[21,22]$. Yet, little is known about the nationwide rate of cholecystectomies in laparoscopic gastric bypass surgery and about the short-term outcomes compared to laparoscopic gastric bypass surgery without concomitant cholecystectomy.

We undertook a secondary data analysis using the Nationwide Inpatient Sample (NIS) database to assess trends in concomitant cholecystectomy among patients undergoing laparoscopic gastric bypass procedures. We also sought to identify potential predictors of concomitant cholecystectomy among patients undergoing laparoscopic gastric bypass surgery and to determine whether there were differences between short-term postoperative outcomes between patients with and without concomitant cholecystectomy.

\section{Methods}

The Institutional Review Board approved the study protocol. We conducted a secondary analysis of data from 2001 to 2008 from a national administrative database, the NIS, a Healthcare Cost and Utilization Project. In the USA, the NIS represents the largest all-payer inpatient database: five to eight million inpatients are included annually. NIS data are based on both clinical discharge diagnosis and resource use for about $20 \%$ of all hospital discharges per year of nonfederal, short-term, general, and other specialty hospitals in the USA. The data set is stratified by various hospital characteristics, such as region, urban/rural locations, teaching status, number of beds, and ownership. All hospital discharges are included in this publicly available, accredited database. No personal identifiers are contained in the NIS.

We identified our sample from the NIS database based on the International Classification of Diseases, 9th Revision, Clinical Modification (ICD-9-CM). All patients 18 years of age or older undergoing laparoscopic gastric bypass surgery for obesity were included. We defined obesity using the following ICD-9 diagnosis codes: V85.3x (body mass index [BMI] $35.0-39.9 \mathrm{~kg} / \mathrm{m}^{2}$ ), V85.4 (BMI $>40 \mathrm{~kg} / \mathrm{m}^{2}$ ), V77.8 (obesity), 278.0 (overweight and obesity), 278.00 (obesity unspecified), 278.01 (morbid obesity), and 278.02 (overweight). Laparoscopic gastric bypass procedure was either defined as ICD-9 44.38 (laparoscopic gastric bypass) or a combination of a procedure code for open gastric bypass $(44.31,44.39$, and 44.3) and either a procedure code for laparoscopy (54.21), laparoscopic cholecystectomy (51.23), laparoscopic lysis of adhesions (54.51), or an ICD-9 diagnosis code for conversion from laparoscopic to open surgery (V64.4, V64.41). Patients with the following ICD-9 diagnosis codes were excluded from our analysis: 253.8 (adiposogenital dystrophy), 259.9 (obesity of endocrine origin NOS), 150 159.9 (gastrointestinal track neoplasm), 555.0-556.9 (inflammatory bowel disease), and 557.0-558.9 (noninfectious colitis). Patients admitted through the emergency department were excluded.

The primary outcome of interest was change from 2001 to 2008 in the proportion of patients who underwent cholecystectomy during a laparoscopic gastric bypass procedure. Patients undergoing concomitant cholecystectomy were identified through ICD-9 procedure codes for cholecystectomy (51.2, 51.21-51.24). Demographic characteristics included age, gender, ethnicity (White, Black, Hispanic, other), ZIP code-related household income per year $(1, \$ 1-34,999 ; 2$, $\$ 35,000-44,999 ; 3, \geq \$ 45,000$ ), and insurance status (Medicare, Medicaid, private including health maintenance organization (HMO), others). Hospital characteristics included hospital region (South, Northeast, Midwest, West), hospital location/teaching status (rural, urban nonteaching, urban teaching), and hospital volume (in quintiles).

We used a modified comorbidity index based on the Charlson index [23], developed for use with administrative data and previously described by Deyo et al. [24]. Patients were divided into three groups: Deyo category 0,1 , or $>1$. Gallbladder disease was identified through the following ICD-9 diagnosis codes: 574.0-574.91 and 575.0-575.9.

We further identified intraoperative and postoperative complications as well as reinterventions through ICD-9 codes as listed in the Appendix modified from Guller et al. [25]. We only included complications that were clearly 
identifiable as postoperative to avoid overlap with preoperative comorbidity. In addition, we captured data on inhospital mortality, discharge status (routine, nonroutine), and length of hospital stay.

\section{Statistical Analysis}

Demographic characteristics were assessed for the entire study period using means and standard deviations or counts and percentages. Comparisons were performed using Student's $t$ test and chi-squared test where appropriate.

We determined the annual incidence of concomitant cholecystectomy by dividing the number of patients undergoing laparoscopic gastric bypass procedures combined with concomitant cholecystectomy by the number of patients undergoing laparoscopic gastric bypass surgery performed for each year. The trend for concomitant cholecystectomy was ascertained using the Cochran-Armitage trend test for all patients undergoing laparoscopic gastric bypass surgery as well as for subgroups of patients with and without gallbladder disease.

To identify predictors of concomitant cholecystectomy, such as year of procedure (to assess changes over time), age, gender, ethnicity, ZIP code-related income, insurance status, hospital region, hospital location/teaching status, hospital volume, Deyo score, and gallbladder disease among patients undergoing laparoscopic gastric bypass surgery, we performed univariate and multivariate logistic regression analysis. Odds ratios (OR) and $95 \%$ confidence intervals $(95 \% \mathrm{CI})$ were calculated.

Using the same predictors as above, we compared intraoperative and postoperative adverse events as well as hospital discharge using univariate and multivariate logistic regression. The same set of covariates was used in multiple linear regression analysis for length of hospital stay. Year of operation was added as a covariate to account for outcome improvements in laparoscopic gastric bypass surgery over time. Since length of hospital stay was substantially skewed to the right, we performed log transformation before performing multiple linear regression analysis. The estimates were retransformed using exponential formula, and median values as well as the $95 \% \mathrm{CI}$ are provided. Due to the very small number of events for retained foreign bodies, bile duct lesions, and mortality, we did not perform multivariate analysis for those outcomes.

Ethnicity was missing for $20.3 \%$ of the subjects. Multivariate regression analyses were, therefore, performed with and without ethnicity in the model. Since the results from the two models were very similar, only the model including ethnicity is presented.

A significance level $(\alpha)$ of 0.05 was used for all analyses. $p$ values for all tests were two-sided. All statistical calculations were performed using Stata/SE version 10 (Stata Corporation, College Station, TX, USA).

\section{Results}

We evaluated data from a total of 70,287 patients undergoing laparoscopic gastric bypass surgery for obesity between 2001 and 2008. There were 57,332 (81.6\%) women and mean age was 43.1 (SD, 10.8) years. Overall, 6,402 (9.1\%) patients underwent concomitant cholecystectomy and 6,245 (8.9\%) patients suffered from any gallbladder disease. Patients who underwent cholecystectomy had fewer comorbidities as measured by the Deyo score before the operation than those who did not. Subject characteristics are provided in Table 1.

The proportion of patients undergoing concomitant cholecystectomy during the laparoscopic gastric bypass procedure decreased from $26.3 \%$ to $3.7 \%$ over the 8 -year time period $(p$ for trend $<0.001$ ) (Table 1, Fig. 1). This trend holds true for both patients with and without gallbladder disease, whereas the trend is more pronounced among patients without gallbladder disease ( $p$ for trend $<0.001$ for both) (Fig. 2a, b).

Using 2001 as reference, year of operation was a strong negative predictor for concomitant cholecystectomy with risk-adjusted OR decreasing from 0.20 (95\% CI, $0.13-$ $0.32 ; p<0.001)$ (relative to 2001) for 2002 to $0.042(95 \%$ CI, $0.028-0.063 ; p<0.001$ ) in 2008 (Table 2). Patients operated in hospitals either located in rural (risk-adjusted OR, $0.51 ; 95 \% \mathrm{CI}, 0.31-0.86 ; p=0.011$ ) or teaching hospitals in urban areas were less likely to undergo cholecystectomy (risk-adjusted OR, $0.54 ; 95 \% \mathrm{CI}, 0.46-0.62 ; p<0.001$ ) compared to urban nonteaching hospitals. The strongest predictor of concomitant cholecystectomy was the presence of any gallbladder disease (risk-adjusted OR, 1,400.1; 95\% CI, $1,187.7-1,650.4 ; p<0.001)$.

Intraoperative complications occurred in $2.37 \%(n=$ $1,516)$ of patients without concomitant cholecystectomy and in $2.86 \%(n=183)$ of patients with concomitant cholecystectomy $(p=0.016)$ (Table 3$)$. After adjusting for multiple confounders, no difference for overall intraoperative complications between the two groups was observed (riskadjusted OR, 1.22; 95\% CI, $0.80-1.85 ; p=0.36$ ). In spite of the fact that the patients who underwent cholecystectomy had fewer comorbidities than those who did not, patients undergoing concomitant cholecystectomy showed a higher rate of postoperative complications $(6.22 \%, n=398)$ than patients without concomitant cholecystectomy $(5.06 \%, n=$ $3,235)(p<0.001)$. Even after adjustment for potential confounders, this difference remained significant (OR, 1.59; 95\% CI, 1.21-2.10; $p=0.001)$. The following postoperative adverse events showed higher risk-adjusted relative OR in patients undergoing concomitant cholecystectomy: postoperative infections (OR, 3.31; 95\% CI, $1.58-6.94 ; p=0.002)$, pulmonary complications (OR, 2.29; 95\% CI, 1.53-3.42; $p<0.001$ ), and gastrointestinal complications (OR, 1.88; $95 \%$ CI, 1.21-2.91; $p=0.005)$. The in-hospital rate of postoperative reinterventions was higher in patients with 
Table 1 Characteristics of patients undergoing laparoscopic gastric bypass surgery for obesity

\begin{tabular}{|c|c|c|c|}
\hline Variable & $\begin{array}{l}\text { Without concomitant } \\
\text { cholecystectomy } \\
(n=63,885,90.89 \%)\end{array}$ & $\begin{array}{l}\text { With concomitant } \\
\text { cholecystectomy } \\
(n=6,402,9.11 \%)\end{array}$ & $p$ value \\
\hline Age (mean, SD) & $43.10(10.9)$ & $42.76(10.5)$ & 0.019 \\
\hline \multicolumn{4}{|l|}{ Gender } \\
\hline Female & $51,874(81.2)$ & $5,458(85.3)$ & \multirow[t]{3}{*}{$<0.001$} \\
\hline Male & $11,713(18.3)$ & $923(14.4)$ & \\
\hline Missing & $298(0.5)$ & $21(0.3)$ & \\
\hline \multicolumn{4}{|l|}{ Ethnicity } \\
\hline White & $38,335(60.0)$ & $4,021(62.8)$ & \multirow[t]{5}{*}{$<0.001$} \\
\hline Black & $5,710(8.9)$ & $474(7.4)$ & \\
\hline Hispanic & $4,488(7.0)$ & $557(8.7)$ & \\
\hline Other & $2,276(3.6)$ & $161(2.5)$ & \\
\hline Missing & $13,076(20.5)$ & $1,189(18.6)$ & \\
\hline \multicolumn{4}{|l|}{ ZIP code-related income } \\
\hline $1-34,999$ & $12,279(19.2)$ & 1,229 (19.2) & \multirow[t]{4}{*}{0.61} \\
\hline $35,000-44,999$ & $16,154(25.3)$ & $1,586(24.8)$ & \\
\hline 44,999 or more & $33,595(52.6)$ & $3,404(53.2)$ & \\
\hline Missing & $1,857(2.9)$ & $183(2.9)$ & \\
\hline \multicolumn{4}{|l|}{ Insurance } \\
\hline Private including HMO & $49,733(77.8)$ & $5,335(83.3)$ & \multirow[t]{5}{*}{$<0.001$} \\
\hline Medicare & $4,502(7.0)$ & $354(5.5)$ & \\
\hline Medicaid & $3,312(5.2)$ & $227(3.6)$ & \\
\hline Other & $6,049(9.5)$ & $475(7.4)$ & \\
\hline Missing & $289(0.5)$ & $11(0.2)$ & \\
\hline \multicolumn{4}{|l|}{ Hospital region } \\
\hline South & 20,191 (31.6) & $1,995(31.2)$ & \multirow[t]{4}{*}{$<0.001$} \\
\hline Northeast & $14,394(22.5)$ & $1,190(18.6)$ & \\
\hline Midwest & $10,083(15.8)$ & $1,099(17.2)$ & \\
\hline West & $19,217(30.1)$ & $2,118(33.1)$ & \\
\hline \multicolumn{4}{|l|}{ Hospital location/teaching } \\
\hline Rural & $1,446(2.3)$ & $160(2.5)$ & \multirow[t]{3}{*}{$<0.001$} \\
\hline Urban nonteaching & $29,373(46.0)$ & $3,545(55.4)$ & \\
\hline Urban teaching & $33,066(51.8)$ & $2,697(42.1)$ & \\
\hline \multicolumn{4}{|l|}{ Hospital volume (quintiles) } \\
\hline <Q1 (1-58) & $12,502(19.6)$ & $1,728(27.0)$ & \multirow[t]{5}{*}{$<0.001$} \\
\hline Q1-Q2 (59-114) & $12,776(20.0)$ & $1,328(20.7)$ & \\
\hline Q2-Q3 (115-173) & $13,324(20.9)$ & $870(13.6)$ & \\
\hline Q3-Q4 (174-289) & $12.924(20.2)$ & $1,065(16.6)$ & \\
\hline$>$ Q4 (>289) & $12,359(19.4)$ & $1,411(22.0)$ & \\
\hline \multicolumn{4}{|l|}{ Deyo score } \\
\hline 0 & $48,881(76.5)$ & $5,090(79.5)$ & \multirow[t]{3}{*}{$<0.001$} \\
\hline$=1$ & $10,914(17.1)$ & $910(14.2)$ & \\
\hline$>1$ & $4,090(6.4)$ & $402(6.3)$ & \\
\hline \multicolumn{4}{|l|}{ Gallbladder disease } \\
\hline Yes & $523(0.82)$ & $5,722(89.38)$ & \multirow[t]{2}{*}{$<0.001$} \\
\hline No & $63,362(99.18)$ & $680(10.62)$ & \\
\hline \multicolumn{4}{|l|}{ Year } \\
\hline 2001 & $498(73.7)$ & $178(26.3)$ & \multirow[t]{2}{*}{$<0.001^{\mathrm{a}}$} \\
\hline 2002 & $2,178(81.4)$ & 497 (18.6) & \\
\hline
\end{tabular}


Table 1 (continued)

\begin{tabular}{lcc}
\hline Variable & $\begin{array}{l}\text { Without concomitant } \\
\text { cholecystectomy } \\
(n=63,885,90.89 \%)\end{array}$ & $\begin{array}{l}\text { With concomitant } \\
\text { cholecystectomy } \\
(n=6,402,9.11 \%)\end{array}$ \\
\hline 2003 & $4,160(73.5)$ & $1,501(26.5)$ \\
2004 & $6,600(83.8)$ & $1,273(16.2)$ \\
2005 & $13,897(93.6)$ & $950(6.4)$ \\
2006 & $11,640(93.1)$ & $868(6.9)$ \\
2007 & $9,920(94.6)$ & $566(5.4)$ \\
2008 & $14,992(96.3)$ & $569(3.7)$
\end{tabular}

Data are provided as number $(n)$ and percentage, if not otherwise indicated. $p$ values are given for $t$ test and chi-squared test as appropriate

${ }^{a}$ Cochran-Armitage trend test, $p$ for trend

concomitant cholecystectomy $(0.73 \%, n=47)$ than in patients without concomitant cholecystectomy $(0.47 \%, n=$ 302) $(p=0.005)$. This difference remained in multivariate regression analysis (risk-adjusted OR, 3.83; 95\% CI, 2.00-7.34; $p<0.001)$. The unadjusted risk of in-hospital mortality was 2.16 times higher for patients undergoing concomitant cholecystectomy than for the others (95\% CI, 1.19-3.94; $p=0.012$ ).

Routine discharge for patients with concomitant cholecystectomy was lower than for patients without concomitant cholecystectomy (risk-adjusted OR, 0.70; 95\% CI, 0.49$1.00 ; p=0.05$ ) (Table 3). Patients undergoing cholecystectomy had a longer risk-adjusted median hospital stay with 2.61 days (95\% CI, 2.55-2.68) than patients without cholecystectomy with 2.22 days (95\% CI, 2.21-2.23) ( $p<0.001)$ (Table 4).

\section{Discussion}

We investigated the trend in the practice of concomitant cholecystectomy during laparoscopic gastric bypass procedures in the USA over an 8-year period. The annual rate of concomitant cholecystectomy decreased significantly in patients both with and without gallbladder disease. When

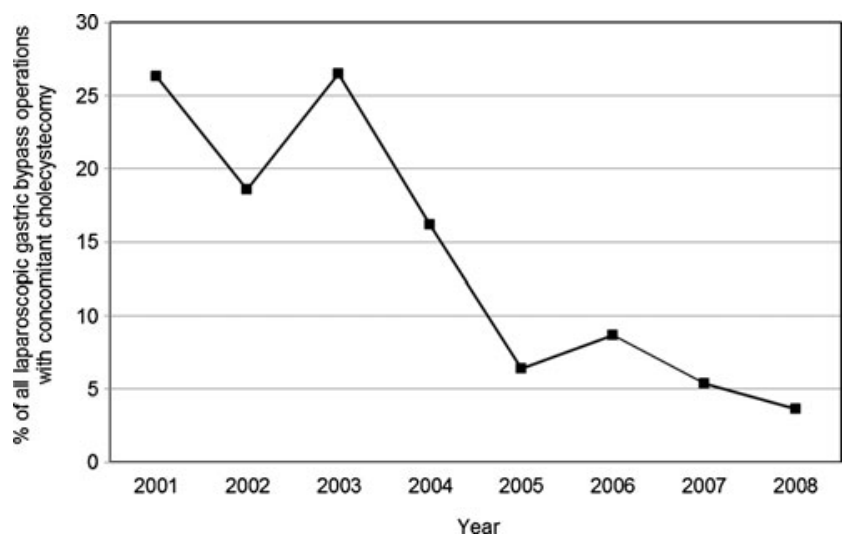

Fig. 1 Percentage of laparoscopic gastric bypass with concomitant cholecystectomy by year; Cochran-Armitage trend test: $p$ for trend $<0.001$ cholecystectomy was performed in addition to laparoscopic gastric bypass surgery, postoperative adverse outcomes were more frequent; in particular, we found an increase in in-hospital mortality and higher rates of infections, pulmonary and gastrointestinal complications, and reinterventions. The duration of hospital stay was longer in patients
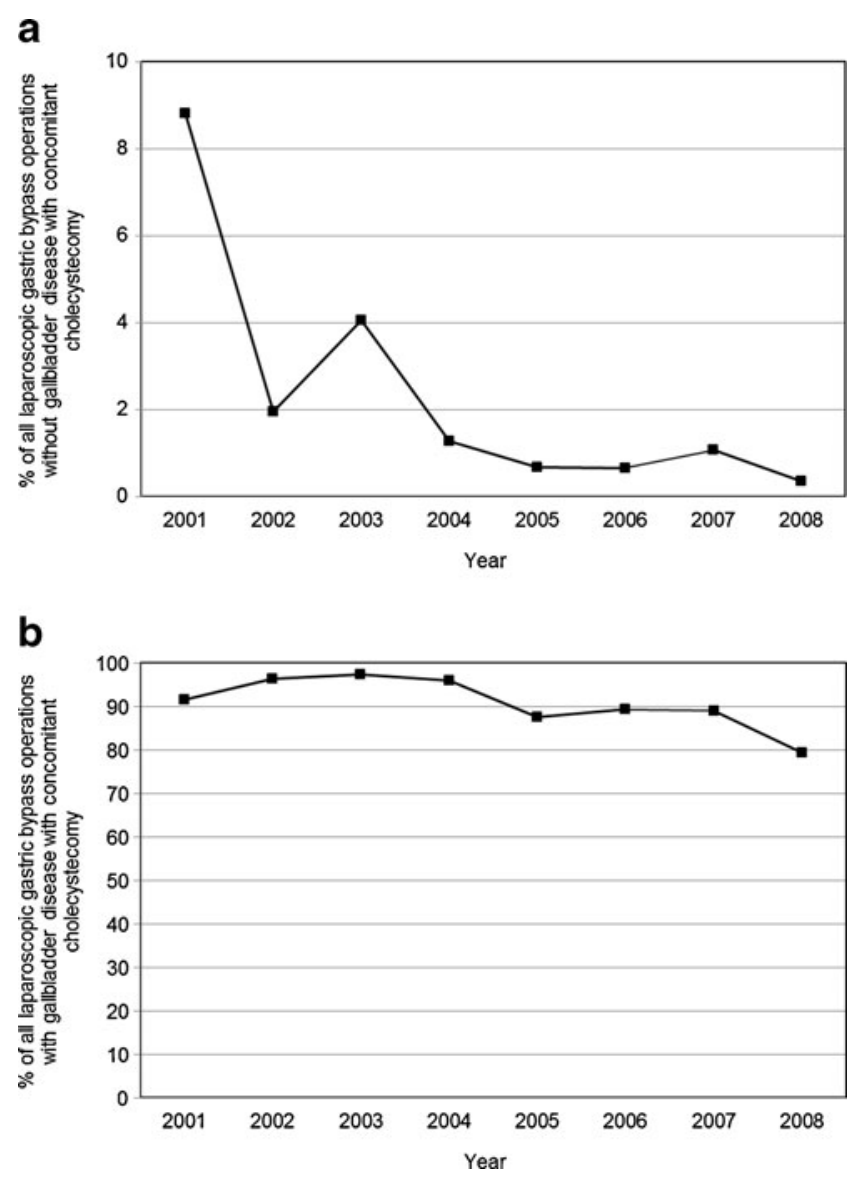

Fig. 2 a Percentage of laparoscopic gastric bypass without gallbladder disease with concomitant cholecystectomy by year; Cochran-Armitage trend test: $p$ for trend $<0.001$. b Percentage of laparoscopic gastric bypass with gallbladder disease with concomitant cholecystectomy by year; Cochran-Armitage trend test: $p$ for trend $<0.001$ 
Table 2 Predictors of concomitant cholecystectomy in patients undergoing laparoscopic gastric bypass

\begin{tabular}{|c|c|c|c|c|}
\hline & Univariate analysis, OR $(95 \% \mathrm{CI})$ & $p$ value & Multivariate analysis, OR $(95 \% \mathrm{CI})$ & $p$ value \\
\hline \multicolumn{5}{|l|}{ Year } \\
\hline 2001 & Ref. & & Ref. & \\
\hline 2002 & $0.64(0.52-0.78)$ & $<0.001$ & $0.20(0.13-0.32)$ & $<0.001$ \\
\hline 2003 & $1.01(0.84-1.21)$ & 0.919 & $0.46(0.31-0.68)$ & $<0.001$ \\
\hline 2004 & $0.54(0.45-0.65)$ & $<0.001$ & $0.16(0.11-0.25)$ & $<0.001$ \\
\hline 2005 & $0.19(0.16-0.23)$ & $<0.001$ & $0.053(0.035-0.080)$ & $<0.001$ \\
\hline 2006 & $0.21(0.17-0.25)$ & $<0.001$ & $0.058(0.038-0.086)$ & $<0.001$ \\
\hline 2007 & $0.16(0.13-0.19)$ & $<0.001$ & $0.077(0.050-0.12)$ & $<0.001$ \\
\hline 2008 & $0.11(0.088-0.13)$ & $<0.001$ & $0.042(0.028-0.063)$ & $<0.001$ \\
\hline Age & $0.997(0.995-0.9995)$ & 0.019 & $1.00(0.0 .99-1.01)$ & 0.96 \\
\hline Gender & & $<0.001$ & & 0.85 \\
\hline Male & Ref. & & Ref. & \\
\hline Female & $1.34(1.24-1.44)$ & & $1.02(0.85-1.22)$ & \\
\hline \multicolumn{5}{|l|}{ Ethnicity } \\
\hline White & Ref. & & Ref. & \\
\hline Black & $0.79(0.72-0.87)$ & $<0.001$ & $1.03(0.82-1.30)$ & 0.78 \\
\hline Hispanic & $1.18(1.08-1.30)$ & $<0.001$ & $0.98(0.77-1.23)$ & 0.83 \\
\hline Other & $0.67(0.57-0.79)$ & $<0.001$ & $0.93(0.64-1.36)$ & 0.72 \\
\hline \multicolumn{5}{|l|}{ ZIP code-related income } \\
\hline 45,000 or more & Ref. & & Ref. & \\
\hline $1-34,999$ & $0.99(0.92-1.06)$ & 0.725 & $1.06(0.89-1.27)$ & 0.51 \\
\hline $35,000-44,999$ & $0.97(0.91-1.03)$ & 0.323 & $1.04(0.89-1.22)$ & 0.62 \\
\hline \multicolumn{5}{|l|}{ Insurance } \\
\hline Private including HMO & Ref. & & Ref. & \\
\hline Medicare & $0.73(0.66-0.82)$ & $<0.001$ & $0.87(0.66-1.17)$ & 0.36 \\
\hline Medicaid & $0.64(0.56-0.73)$ & $<0.001$ & $0.73(0.51-1.03)$ & 0.07 \\
\hline Other & $0.73(0.66-0.81)$ & $<0.001$ & $1.13(0.88-1.45)$ & 0.34 \\
\hline \multicolumn{5}{|l|}{ Hospital region } \\
\hline South & Ref. & & Ref. & \\
\hline Northeast & $0.84(0.78-0.90)$ & $<0.001$ & $0.68(0.56-0.83)$ & $<0.001$ \\
\hline Midwest & $1.10(1.02-1.19)$ & 0.013 & $0.60(0.45-0.79)$ & $<0.001$ \\
\hline West & $1.12(1.05-1.19)$ & 0.001 & $0.69(0.57-0.83)$ & $<0.001$ \\
\hline \multicolumn{5}{|c|}{ Hospital location/teaching status } \\
\hline Urban nonteaching & Ref. & & Ref. & \\
\hline Rural & $0.92(0.78-1.08)$ & 0.31 & $0.51(0.31-0.86)$ & 0.011 \\
\hline Urban teaching & $0.68(0.64-0.71)$ & $<0.001$ & $0.54(0.46-0.62)$ & $<0.001$ \\
\hline \multicolumn{5}{|l|}{ Deyo score } \\
\hline 0 & Ref. & & Ref. & \\
\hline$=1$ & $0.78(0.74-0.83)$ & $<0.001$ & $0.83(0.72-0.96)$ & 0.014 \\
\hline$>1$ & $0.64(0.57-0.71)$ & $<0.001$ & $0.86(0.66-1.14)$ & 0.30 \\
\hline \multicolumn{5}{|l|}{ Gallbladder disease } \\
\hline No & Ref. & & Ref. & \\
\hline Yes & $1019.5(906.7-1146.2)$ & $<0.001$ & $1400.1(1187.7-1650.4)$ & $<0.001$ \\
\hline
\end{tabular}

Adjustment for age, gender, ethnicity, Deyo score, gallbladder disease, ZIP code-related income, hospital volume, hospital location/teaching status, hospital region, insurance status, and year of operation. Total number of patients in the multivariate analysis: $n=54,124$

undergoing concomitant cholecystectomy compared with those only undergoing laparoscopic gastric bypass surgery.
Definitive consensus on whether concomitant cholecystectomy should be performed does not yet exist. Still, some 
Table 3 Short-term outcomes after laparoscopic gastric bypass procedure with and without concomitant cholecystectomy (reference category)

\begin{tabular}{|c|c|c|c|c|c|c|}
\hline & $\begin{array}{l}\text { Without concomitant } \\
\text { cholecystectomy } \\
(n=63,885,90.89 \%)\end{array}$ & $\begin{array}{l}\text { With concomitant } \\
\text { cholecystectomy } \\
(n=6,402,9.11 \%)\end{array}$ & $\begin{array}{l}\text { Unadjusted } \\
\text { analysis, OR } \\
(95 \% \mathrm{CI})\end{array}$ & $p$ value & $\begin{array}{l}\text { Adjusted } \\
\text { analysis }{ }^{\mathrm{a}}, \text { OR } \\
(95 \% \mathrm{CI})\end{array}$ & $p$ value \\
\hline \multicolumn{7}{|l|}{ Intraoperative complications } \\
\hline Injury to adjacent structures & $644(1.01)$ & $89(1.39)$ & $1.38(1.11-1.73)$ & 0.004 & $0.94(0.50-1.77)$ & 0.85 \\
\hline Retained foreign body & $17(0.03)$ & $5(0.08)$ & $2.94(1.08-7.96)$ & 0.034 & N/A & N/A \\
\hline Hemorrhage complicating procedure & $890(1.39)$ & $99(1.55)$ & $1.11(0.90-1.37)$ & 0.32 & $1.25(0.73-2.15)$ & 0.41 \\
\hline Bile duct complications & $3(0.005)$ & $2(0.03)$ & $6.65(1.11-39.82)$ & 0.038 & N/A & N/A \\
\hline Overall & $1,516(2.37)$ & $183(2.86)$ & $1.21(1.04-1.41)$ & 0.016 & $1.22(0.80-1.85)$ & 0.36 \\
\hline \multicolumn{7}{|l|}{ Postoperative complications } \\
\hline Mechanical wound complications & $318(0.50)$ & $32(0.50)$ & $1.00(0.70-1.45)$ & 0.98 & $1.62(0.69-3.84)$ & 0.27 \\
\hline Infections & $266(0.42)$ & $49(0.77)$ & $1.84(1.36-2.50)$ & $<0.001$ & $3.31(1.58-6.94)$ & 0.002 \\
\hline Urinary/renal complications & $217(0.34)$ & $27(0.42)$ & $1.24(0.83-1.86)$ & 0.29 & $2.28(0.90-5.82)$ & 0.08 \\
\hline Pulmonary complications & $1,087(1.70)$ & $150(2.34)$ & $1.39(1.17-1.65)$ & $<0.001$ & $2.29(1.53-3.42)$ & $<0.001$ \\
\hline Gastrointestinal complications & $1,122(1.76)$ & $143(2.23)$ & $1.28(1.07-1.52)$ & 0.006 & $1.88(1.21-2.91)$ & 0.005 \\
\hline Cardiovascular complications & $628(0.98)$ & $71(1.11)$ & $1.13(0.88-1.45)$ & 0.33 & $1.55(0.82-2.93)$ & 0.17 \\
\hline Systemic complications & $302(0.47)$ & $33(0.52)$ & $1.09(0.76-1.56)$ & 0.64 & $0.90(0.35-2.35)$ & 0.83 \\
\hline Overall & $3,235(5.06)$ & $398(6.22)$ & $1.24(1.12-1.38)$ & $<0.001$ & $1.59(1.21-2.10)$ & 0.001 \\
\hline Mortality & $60(0.09)$ & $13(0.2)$ & $2.16(1.19-3.94)$ & 0.012 & N/A & N/A \\
\hline Reintervention & $302(0.47)$ & $47(0.73)$ & $1.56(1.14-2.12)$ & 0.005 & $3.83(2.00-7.34)$ & $<0.001$ \\
\hline Conversion rate & $1,201(1.88)$ & $190(2.97)$ & $1.60(1.37-1.86)$ & $<0.001$ & $1.487(0.998-2.230)$ & 0.07 \\
\hline \multicolumn{7}{|l|}{ Discharge status ${ }^{\mathrm{b}}$} \\
\hline Nonroutine discharge & $2,021(3.17)$ & $263(4.12)$ & Ref. & & Ref. & \\
\hline Routine discharge & $61,751(96.83)$ & $6,121(95.88)$ & $0.76(0.67-0.87)$ & $<0.001$ & $0.70(0.49-1.00)$ & 0.05 \\
\hline
\end{tabular}

Due to small outcome events for retained foreign body, bile duct lesions, and mortality, multivariate analysis was not performed for those outcomes ${ }^{a}$ Adjustment for age, gender, ethnicity, Deyo score, gallbladder disease, ZIP code-related income, hospital volume, hospital location/teaching status, hospital region, insurance status, and year of operation

${ }^{\mathrm{b}} 113$ patients in the group without concomitant cholecystectomy and 18 patients in the group with concomitant cholecystectomy have unknown discharge status

authors suggest that every patient should undergo prophylactic cholecystectomy during laparoscopic gastric bypass surgery $[13,17,26]$, while others favor cholecystectomy only after preoperative confirmation of gallstones [16, 27]. However, there is increasing evidence that cholecystectomy should only be performed in symptomatic patients since symptomatic gallbladder disease necessitating cholecystectomy following laparoscopic gastric bypass surgery is as low as $7 \%$ to $15 \%[11,19,22,28-30]$. The limited need for cholecystectomy in the early follow-up period after bariatric surgery is in stark contrast to the much higher incidence of gallstone formation of $30 \%$ to $53 \%$ within

Table 4 Median length of hospital stay with and without concomitant cholecystectomy

\begin{tabular}{|c|c|c|c|c|c|c|}
\hline & \multicolumn{3}{|l|}{ Unadjusted } & \multicolumn{3}{|l|}{ Adjusted } \\
\hline & $\begin{array}{l}\text { Without concomitant } \\
\text { cholecystectomy }\end{array}$ & $\begin{array}{l}\text { With concomitant } \\
\text { cholecystectomy }\end{array}$ & $p$ value & $\begin{array}{l}\text { Without concomitant } \\
\text { cholecystectomy }\end{array}$ & $\begin{array}{l}\text { With concomitant } \\
\text { cholecystectomy }\end{array}$ & $p$ value \\
\hline Length of hospital stay & $2.23(2.22-2.24)$ & $2.50(2.47-2.53)$ & $<0.001$ & $2.22(2.21-2.23)$ & $2.61(2.55-2.68)$ & $<0.001$ \\
\hline
\end{tabular}


1 year of the operation $[11,12]$, but highlights the fact that not all patients with gallstones require cholecystectomy. However, the growing evidence that a cholecystectomy after a laparoscopic gastric bypass procedure can be done in a minimally invasive fashion with low morbidity is most likely responsible for the significant decrease in concomitant cholecystectomy $[11,16,19,22,28,31]$. The situation was different in the era of open gastric bypass procedures where a postoperative cholecystectomy was difficult to perform in a minimally invasive fashion and a second open procedure was often inevitable. Descriptions of laparoscopic revisions after open bariatric surgery are not available before $2001[32,33]$.

Our findings suggest that, even if the overall inhospital mortality rate is very low, $0.1 \%$, the mortality rate is significantly higher in patients undergoing concomitant cholecystectomy. Earlier single-center studies have demonstrated equal mortality rates for patients with and without concomitant cholecystectomy [16, 17, 26, 34]. The use of a large national registry such as the NIS allows for the detection of even small effects. In our study, the mortality risk is about twice as high for patients undergoing concomitant cholecystectomy compared with patients who are not.

Despite similar rates of intraoperative complications in the two groups, we demonstrate that rates of postoperative complications and reinterventions are higher among patients undergoing concomitant cholecystectomy. In particular, this is true for postoperative infections, pulmonary and gastrointestinal complications, and reinterventions. The findings of Hamad and colleagues are consistent with these findings, suggesting that major early postoperative complications in patients undergoing concomitant cholecystectomy are more frequent than in patients not undergoing cholecystectomy [34]. Nonetheless, others have suggested no difference in adverse postoperative outcomes [17, 26, 27, 35]. Even though the absolute risk of those complications in our study is low, an overall 1.6-fold increase in relative risk still remains. For bariatric patients, the laparoscopic view is often impaired through increased visceral fat and hepatomegaly. Additionally, adding a cholecystectomy to the already difficult laparoscopic gastric bypass procedure increases operative time [27, 31] and tissue damage. This may reduce the function of the right diaphragm and can lead to increased postoperative pain [36]. The overall lower preoperative Deyo score among patients undergoing concomitant cholecystectomy suggests that their higher rate of complications postoperatively may be primarily due to the operation itself rather than the preoperative differences in comorbidities between the two patient groups.

Postoperative hospital stay was increased by approximately 0.4 days for patients undergoing concomitant cholecystectomy. This finding concurs with those of others who have demonstrated hospital stays that are 0.6 to 1.7 days longer for these patients $[31,34]$. In contrast, others did not find any differences in postoperative stay [16, 17, 26, 27]. Even if the increase in length of hospital stay for patients undergoing concomitant cholecystectomy is small, it should not be neglected. These findings are consistent with those of Hamad and colleagues who found a significantly higher major early postoperative complication rate together with prolonged hospital stay [34].

This study has several potential limitations. We were limited by the variables available in the data set. Therefore, even though multivariable regression analysis is able to adjust for the measured confounding variables, unmeasured confounding may still be possible. For example, some known risk factors for adverse outcomes are unmeasured in NIS, such as BMI. In addition, the clinical encounter in the NIS is limited to a single inpatient stay and, as such, does not capture complications after hospital discharge. The incidence of cholecystectomy after bariatric surgery is thus also unknown. The strengths of this analysis are the inclusion of a national cohort and a large sample size and, therefore, broad generalizability and the power to detect even small effects.

\section{Conclusions}

In essence, the proportion of patients in the USA undergoing laparoscopic gastric bypass surgery with concomitant cholecystectomy has decreased significantly over time. Given the much higher rate of adverse short-term postoperative outcomes in patients undergoing concomitant cholecystectomy and laparoscopic gastric bypass surgery relative to those undergoing laparoscopic gastric bypass surgery alone, our findings suggest that concomitant cholecystectomy should only be indicated for patients with symptomatic gallbladder disease.

Acknowledgment The authors acknowledge the Team "Research on Research" for the templates for writing the introduction and discussion sections of the manuscript [37] and the templates for literature review [38].

Financial Disclosure/Funding Support This work was supported by grant PBBEP3-131567 from the Swiss National Science Foundation (MW). The authors have no other potential conflicts of interest, including specific financial interests and relationships and affiliations relevant to the subject matter or materials discussed in the manuscript.

Conflicts of Interest All contributing authors, including Mathias Worni, Ulrich Guller, Anand Shah, Mihir Gandhi, Jatin Shah, Dimple Rajgor, Ricardo Pietrobon, Danny O. Jacobs, and Truls Østbye, declare that they have no conflicts of interest in relation to this manuscript. 


\section{Appendix}

Table 5 Intraoperative and postoperative complications as well as reinterventions identified through ICD-9-CM codes

ICD-9-CM

code

Intraoperative complication

Injury to adjacent structures, accidental puncture

998.2

or laceration complicating surgery

Retained foreign body

\section{4}

Hemorrhage complicating procedure

998.11

Bile duct complications

Obstruction of bile duct (that with calculus is

excluded here)

Perforation of bile duct

576.2

Fistula of bile duct

Unspecified disorder of biliary tract

Postoperative complications

Mechanical wound complications

Postoperative hematoma

Postoperative seroma (noninfected)

998.13

Disruption of operative wound

Disruption of wound unspecified

Disruption of internal operation (surgical) wound

Disruption of external operation (surgical) wound

Persistent postoperative fistula

Delayed wound healing

Infections

Postoperative infection

Postoperative infected seroma

Postoperative skin abscess/infection

Postoperative septic wound complications

Postoperative intra-abdominal/subdiaphragmatic

abscess

Urinary/renal complications

Postoperative urinary retention

576.3

576.4

576.9

Postoperative urinary tract infection

Acute renal failure

Pulmonary complications

Postoperative acute pneumothorax

Postoperative pulmonary edema

Adult respiratory distress syndrome following surgery

Transfusion-related acute lung injury

Postoperative atelectasis/pneumonia

Mendelson's syndrome resulting from a procedure

Gastrointestinal complications

Postoperative vomiting

Diarrhea following gastrointestinal surgery

Postoperative small bowel obstruction/ileus

(requiring nasogastric tube)

Complication of anastomosis of gastrointestinal tract

Cardiovascular complications

Postoperative hypotension

998.3

998.30

998.31

998.32

998.6

998.83

998.5

998.51

998.59

998.59

998.59

997.5

997.5

997.5

512.1

518.4

518.5

518.7

997.3

997.3

564.3

564.4

997.4

997.4

458.29
Table 5 (continued)

\begin{tabular}{lc}
\hline & $\begin{array}{l}\text { ICD-9-CM } \\
\text { code }\end{array}$ \\
\hline $\begin{array}{l}\text { Postoperative stroke } \\
\text { Cardiac arrest/insufficiency during or resulting } \\
\text { from a procedure }\end{array}$ & 997.02 \\
Phlebitis or thrombophlebitis from procedure & 997.1 \\
Systemic complications & 997.2 \\
Postoperative shock & \\
Postoperative fever & 998.0 \\
Unspecified complication of procedure, not & 998.89 \\
elsewhere classified & 998.9 \\
$\begin{array}{l}\text { Blood transfusion } \\
\text { Reinterventions }\end{array}$ & 99.04 \\
$\begin{array}{l}\text { Exploratory laparotomy } \\
\text { Reopening of recent laparotomy site for control of } \\
\text { hemorrhage, exploration, incision of hematoma }\end{array}$ & 54.11 \\
$\begin{array}{l}\text { Drainage of intraperitoneal abscess or hematoma } \\
\text { Reclosure of postoperative disruption of abdominal wall }\end{array}$ & 54.12 \\
$\begin{array}{l}\text { Percutaneous drainage of abdomen } \\
\text { Removal of foreign body from peritoneal cavity }\end{array}$ & 54.19 \\
\hline
\end{tabular}

\section{References}

1. Flegal KM, Carroll MD, Ogden CL, et al. Prevalence and trends in obesity among US adults, 1999-2008. JAMA. 2010;303:235-41.

2. Santry HP, Gillen DL, Lauderdale DS. Trends in bariatric surgical procedures. JAMA. 2005;294:1909-17.

3. Kohn GP, Galanko JA, Overby DW, et al. Recent trends in bariatric surgery case volume in the United States. Surgery. 2009;146:37580.

4. Sjostrom L, Narbro K, Sjostrom CD, et al. Effects of bariatric surgery on mortality in Swedish obese subjects. N Engl J Med. 2007;357:741-52.

5. Puzziferri N, Nakonezny PA, Livingston EH, et al. Variations of weight loss following gastric bypass and gastric band. Ann Surg. 2008;248:233-42.

6. Christou NV, Sampalis JS, Liberman M, et al. Surgery decreases long-term mortality, morbidity, and health care use in morbidly obese patients. Ann Surg. 2004;240:416-23. discussion 423-4.

7. Keating CL, Dixon JB, Moodie ML, et al. Cost-effectiveness of surgically induced weight loss for the management of type 2 diabetes: modeled lifetime analysis. Diabetes Care. 2009;32:56774.

8. Gustafsson U, Benthin L, Granstrom L, et al. Changes in gallbladder bile composition and crystal detection time in morbidly obese subjects after bariatric surgery. Hepatology. 2005;41:1322-8.

9. Dittrick GW, Thompson JS, Campos D, et al. Gallbladder pathology in morbid obesity. Obes Surg. 2005; 15:238-42.

10. Everhart JE. Contributions of obesity and weight loss to gallstone disease. Ann Intern Med. 1993;119:1029-35.

11. Villegas L, Schneider B, Provost D, et al. Is routine cholecystectomy required during laparoscopic gastric bypass? Obes Surg. 2004;14:206-11.

12. Adami Chaim E, da Silva BB, de Oliveira CIgleziasBrandao. Impact of rapid weight reduction on risk of cholelithiasis after bariatric surgery. Obes Surg. 2003;13:625-8. 
13. Nougou A, Suter M. Almost routine prophylactic cholecystectomy during laparoscopic gastric bypass is safe. Obes Surg. 2008;18:5359.

14. Liem RK, Niloff PH. Prophylactic cholecystectomy with open gastric bypass operation. Obes Surg. 2004;14:763-5.

15. Fobi M, Lee H, Igwe D, et al. Prophylactic cholecystectomy with gastric bypass operation: incidence of gallbladder disease. Obes Surg. 2002;12:350-3.

16. Tucker ON, Fajnwaks P, Szomstein S, et al. Is concomitant cholecystectomy necessary in obese patients undergoing laparoscopic gastric bypass surgery? Surg Endosc. 2008;22:2450-4.

17. Kim JJ, Schirmer B. Safety and efficacy of simultaneous cholecystectomy at Roux-en-Y gastric bypass. Surg Obes Relat Dis. 2009;5:48-53.

18. Scott DJ, Villegas L, Sims TL, et al. Intraoperative ultrasound and prophylactic ursodiol for gallstone prevention following laparoscopic gastric bypass. Surg Endosc. 2003;17:1796-802.

19. Swartz DE, Felix EL. Elective cholecystectomy after Roux-en-Y gastric bypass: why should asymptomatic gallstones be treated differently in morbidly obese patients? Surg Obes Relat Dis. 2005; 1:555-60.

20. Miller K, Hell E, Lang B, et al. Gallstone formation prophylaxis after gastric restrictive procedures for weight loss: a randomized double-blind placebo-controlled trial. Ann Surg. 2003;238:697-702.

21. Patel KR, White SC, Tejirian T, et al. Gallbladder management during laparoscopic Roux-en-Y gastric bypass surgery: routine preoperative screening for gallstones and postoperative prophylactic medical treatment are not necessary. Am Surg. 2006;72:857-61.

22. D'Hondt M, Sergeant G, Deylgat B, et al. Prophylactic cholecystectomy, a mandatory step in morbidly obese patients undergoing laparoscopic Roux-en-Y gastric bypass? J Gastrointest Surg. 2011;15:1532-6.

23. Charlson ME, Pompei P, Ales KL, et al. A new method of classifying prognostic comorbidity in longitudinal studies: development and validation. J Chronic Dis. 1987;40:373-83.

24. Deyo RA, Cherkin DC, Ciol MA. Adapting a clinical comorbidity index for use with ICD-9-CM administrative databases. J Clin Epidemiol. 1992;45:613-9.

25. Guller U, Hervey S, Purves H, et al. Laparoscopic versus open appendectomy: outcomes comparison based on a large administrative database. Ann Surg. 2004;239:43-52.
26. Ahmed AR, O'Malley W, Johnson J, et al. Cholecystectomy during laparoscopic gastric bypass has no effect on duration of hospital stay. Obes Surg. 2007;17:1075-9.

27. Escalona A, Boza C, Munoz R, et al. Routine preoperative ultrasonography and selective cholecystectomy in laparoscopic Roux-enY gastric bypass. Why not? Obes Surg. 2008;18:47-51.

28. Papasavas PK, Gagne DJ, Ceppa FA, et al. Routine gallbladder screening not necessary in patients undergoing laparoscopic Roux-en-Y gastric bypass. Surg Obes Relat Dis. 2006;2:41-6. discussion 46-7.

29. Ellner SJ, Myers TT, Piorkowski JR, et al. Routine cholecystectomy is not mandatory during morbid obesity surgery. Surg Obes Relat Dis. 2007;3:456-60.

30. Li VK, Pulido N, Martinez-Suartez P, et al. Symptomatic gallstones after sleeve gastrectomy. Surg Endosc. 2009;23:2488-92.

31. Patel JA, Patel NA, Piper GL, et al. Perioperative management of cholelithiasis in patients presenting for laparoscopic Roux-en-Y gastric bypass: have we reached a consensus? Am Surg. 2009;75:470-6. discussion 476.

32. de Csepel J, Nahouraii R, Gagner M. Laparoscopic gastric bypass as a reoperative bariatric surgery for failed open restrictive procedures. Surg Endosc. 2001;15:393-7.

33. McCormick JT, Papasavas PK, Caushaj PF, et al. Laparoscopic revision of failed open bariatric procedures. Surg Endosc. 2003;17:413-5.

34. Hamad GG, Ikramuddin S, Gourash WF, et al. Elective cholecystectomy during laparoscopic Roux-en-Y gastric bypass: is it worth the wait? Obes Surg. 2003;13:76-81.

35. Guadalajara H, Sanz Baro R, Pascual I, et al. Is prophylactic cholecystectomy useful in obese patients undergoing gastric bypass? Obes Surg. 2006;16:883-5.

36. Hendolin HI, Paakonen ME, Alhava EM, et al. Laparoscopic or open cholecystectomy: a prospective randomised trial to compare postoperative pain, pulmonary function, and stress response. Eur J Surg. 2000;166:394-9.

37. Shah J, Shah A, Pietrobon R. Scientific writing of novice researchers: what difficulties and encouragements do they encounter? Acad Med. 2009;84:511-6.

38. Pietrobon R, Guller U, Martins H, et al. A suite of web applications to streamline the interdisciplinary collaboration in secondary data analyses. BMC Med Res Methodol. 2004;4:29. 